\title{
ANALISIS SENTIMEN TWEET MENGGUNAKAN BACKPROPAGATION NEURAL NETWORK
}

\author{
Maulana Aziz Assuja ${ }^{1)}$, Saniati ${ }^{2)}$ \\ ${ }^{1,2)}$ Program Studi Teknik Informatika, STMIK Teknokrat Lampung \\ Jl. H. Zainal Abidin Pagaralam No. 9 - 11 Kedaton Bandar Lampung 35141 \\ Telp. (0721) 774061, 702022 (hunting) \\ aziz.maulana.assuja@gmail.com ${ }^{1)}$, saniati@teknokrat.ac.id ${ }^{2)}$
}

\begin{abstract}
Abstrak
Analisis sentimen tweet berkembang sebagai sebuah kajian pada bidang Pengolahan Bahasa Alami yang bermanfaat mengetahui opini masyarakat terhadap sebuah topik tertentu secara otomatis. Pada penelitian ini kami mengajukan teknik analisis tweet kedalam tiga kelas (positif, negatif dan netral) menggunakan algoritma Backpropagation Neural Network. Input jaringan merupakan sejumlah kata terpilih yang dirangking mengunakan skor TF*IDF. Variasi praproses term dilakukan untuk menguji performa klasifikasi sentimen. Hasil pengujian menunjukkan metode yang kami ajukan berhasil melakukan klasifikasi dengan hasil terbaik dengan akurasi $78.34 \%$ dan presisi $84.21 \%$.
\end{abstract}

\section{Kata kunci: Analisis sentimen, Tweet,}

\section{Backpropagation, Neural Network}

\section{Pendahuluan}

Twitter merupakan microblog yang banyak digunakan oleh penggunanya untuk berkomunikasi dan mengungkapkan pendapatnya (tweet) tentang topik tertentu. Berdasarkan tweet-tweet komentar yang dihasilkan, dapat ditangkap beberapa opini dari tweeter, baik berupa pernyataan positif, negatif atau bahkan netral (non opini). Dengan jumlah data yang relativ banyak, tweeter yang berasal dari berbagai sumber (terdistribusi), dan waktu penyajian yang realtime, maka pendapat/sentimen dari para tweeter ini dapat dimanfaatkan untuk berbagai hal, diantaranya mengetahui kepuasan atau keluhan user terhadap suatu produk atau layanan, menganalisa tren produk yang populer, melihat tingkat popularitas artis/politikus/tokoh, dsb.

Berdasarkan manfaat-manfaat tersebut maka penelitian tentang sentimen analisis pun banyak dilakukan yang sejak lebih kurang tahun 2002 [4][13] dan menjadi pembahasan penting pada bidang Pengolahan Bahasa Alami. Sentiment analysis atau biasa disebut juga opinion mining bertujuan mempelajari tentang pendapat, sentimen dan emosi yang diekspresikan pada teks [3].

Banyak metode yang digunakan untuk menerapkan sentiment analisis diantaranya dengan pendekatan supervised learning seperti Naive Bayes [9][4][2][12], Support Vector Machine (SVM)[1][12][4][2][11], Maximum Entrophy [4] [2], Neural Network [5][14] dan unsupervised learning[13][17][6]. Task utama dalam sentimen analisis yaitu mengklasifikasi teks tweet kedalam salah satu kelas yaitu positif, negatif atau netral. Pada penelitian ini digunakan pendekatan supervised learning dengan algoritma Backpropagatiaon Neural Network (BNN) yang merupakan varian dari Artificial Neural Network dan telah banyak berhasil diaplikasikan termasuk pada masalah klasifikasi[16]. BNN melakukan pembelajaran dengan menyesuaikan bobot dari tiap perceptron jaringannya sehingga sesuai (menggunakan batas toleransi atau iterasi) dengan data trainingnya.

Klasifikasi pada teks umumnya menggunakan beberapa fitur yang mampu menjadi ciri pengelompokan yang baik seperti leksikon atau term[4][10][2][5] baik secara unigram, bigram, emoticon[12][17], POS tag[4][2][1], hash tag[1] dan lain sebagainya. Leksikon atau term dalam teks merupakan fitur yang paling banyak digunakan, namun pemilihannya sebagai representasi tiap kelas target menjadi tidak konsisten jika jumlah data trainingnya berubah. Untuk mendapatkan term-term yang paling relevan tersebut dengan jumlah yang konsisten, maka pada penelitian digunakan perangkingan term terbaik menggunakan teknik TF*IDF (Term Frequency Invers Document Frequency) seperti pada beberapa penelitian sebelumnya[10][12].

\section{Tinjauan Pustaka}

\subsection{Sentimen Analisis}

Sentimen analisis atau opinion mining didefinisikan sebagai bidang ilmu yang mempelajari bagaimana mengekspresikan sentimen, opini atau pendapat dan emosi yang diekpresikan didalam teks [3]. Terdapat beberapa topik pembahasan dalam sentimen analisis, salah satu yang paling sering diteliti yaitu klasifikasi sentimen. Topik ini berfokus pada kegiatan pengelompokan sentimen berdasarkan teks opini terhadap pembahasan masalah tertentu (movie, produk, tokoh, kejadian, dsb).

Beberapa penelitian melakukan pengelompok-an menjadi beberapa jenis kelas target, 1)dengan dua kelas (positif dan negatif) [4][2][6][11] [5]; 2)tiga kelas (positif, negatif dan netral)[7][1][12], dan 3)lima kelas (sangat negatif, negatif, netral, positif dan sangat positif)[5]. Namun menurut riset Go [2] yang melakukan klasifikasi kedalam kelas negatif dan positif saja, menyimpulkan jika pengelompokan kedalam kelas netral tetap perlu dilakukan, karena pada beberapa tweet 
ditemukan sentimen yang tidak cenderung bernilai positif maupun negatif.

\subsection{Tweets}

Sentimen analisis dilakukan terhadap opini yang diberikan terhadap review pembahasan tertentu, yang pada masa kekinian, banyak orang mengomentari banyak hal dengan memanfaatkan media sosial online seperti twitter. Pada twitter tiap orang yang terdaftar dapat mengirimkan dan membaca teks pendek yang biasa disebut tweet.

Tweet memiliki karakteristik yang unik berdasarkan laporan analisis Go [2] baik pada panjang teks, ketersediaan data, model bahasa, dan domain. Panjang teks pada tweet maksimum 140 karakter dengan rata-rata tweet terdiri dari 14 kata atau 78 karakter. Ketersediaan data, dengan Twitter API dapat dikumpulkan begitu banyak tweet sebagai data set. Model bahasa pada tweet tidak terstruktur bahkan terkadang ada kesalahan pengetikan. Serta domain pembahasan pada twitter sangat luas terhadap banyak sekali topik apapun, berbeda dengan penelitian lain pada domain terbatas seperti review movie.

\subsection{TF*IDF (Term Frequency Invers Document Frequency)}

TF*IDF merupakan teknik pembobotan kata yang berbasis pada statistik kemunculan kata dan tingkat kepentingan dokumen yang mengandungnya. Pembobotan yang diadaptasi dari pendekatan temukembali informasi (information retrieval)[8] ini merupakan hasil dari perkalian term frequency dan inverse document frequency yang tiap nilainya didapatkan dengan persamaan (1).

$$
T F * I D F=T F\left(w_{i}, d\right) * I D F\left(w_{i}\right)
$$

\section{Dimana:}

$\mathrm{w}_{\mathrm{i}}=$ kata ke $\mathrm{i}$

$\mathrm{d}=$ dokumen

$\mathrm{TF}\left(\mathrm{w}_{\mathrm{i}}, \mathrm{d}\right)=$ jumlah kemunculan kata $\mathrm{w}_{\mathrm{i}}$ pada dokumen $\mathrm{d}$ $\operatorname{IDF}\left(\mathrm{w}_{\mathrm{i}}\right)=$ Invers Document Frequency dari kata wi.

Pembobotan dihitung untuk tiap kata, Term Frequency menunjukkan bahwa semakin tinggi kemunculan kata pada sebuah dokumen maka semakin penting kata tersebut mewakili dokumen. Nilai Inverse Document Frequency memberikan indikasi bahwa jika kemunculan sebuah kata mempunyai frekuensi yang tinggi pada dokumen tertentu saja maka kata tersebut menjadi ciri penting dan mewakili dokumen tersebut. Sedangkan jika kata muncul pada seluruh dokumen maka kata tersebut bersifat umum atau tidak mewakili dokumen manapun dan memiliki nilai IDF 0. Dimana nilai IDF dapat didapatkan dengan persamaan (2).

$$
\operatorname{IDF}\left(\mathrm{w}_{\mathrm{i}}\right)=\log \frac{|\mathrm{D}|}{\mathrm{DF}\left(\mathrm{w}_{\mathrm{i}}\right)}
$$

Dimana:

$\mathrm{w}_{\mathrm{i}}=$ kata ke $\mathrm{i}$

$|\mathrm{D}|=$ jumlah seluruh dokumen

$\operatorname{IDF}\left(\mathrm{w}_{\mathrm{i}}\right)=$ jumlah dokumen yang mengandung kata $\mathrm{w} i$.

Pada penelitian sentimen analisis, penggunaan dokumen pada persamaan diwakili oleh tweet yang digunakan. Pembobotan TF*IDF membantu mengambil kata-kata dari tweet yang paling mewakili kelasnya.

\subsection{Neural Network}

Penelitian sentimen analisis dengan pendekatan supervised learning dengan varian metode Artificial Neural Network [5][14] menunjukkan hasil yang baik lebih dari $80 \%$ bahkan mencapai $86 \%$ [5]. Pada penelitian klasifikasi lainnya (kelas gramatical dan ungramatical)[15] juga menunjukkan hasil yang mencapai lebih dari 95\%. Hal ini menunjukkan jika pendekatan Artificial Neural Network memberikan hasil yang memuaskan karena termasuk metode mampu menangani training sample dengan noise yang banyak (kebutuhan akan sistem yang robust terhadap noise)[16].

Backpropagation Neural Network (BNN) adalah versi modifikasi Artificial Neural Network yang menambahkan propagasi error dengan bergerak mundur (dari lapisan output menuju lapisan input). Penggunaan propagasi balik dapat mempercepat konvergensi sehingga model dengan jumlah data input yang banyak pun dapat dengan cepat didapatkan. Hal ini berkaitan dengan jumlah layer dan jumlah data input pada arsitektur klasifikasi yang digunakan, karena penelitian sebelumnya data input dapat berjumlah banyak tergantung levelnya.

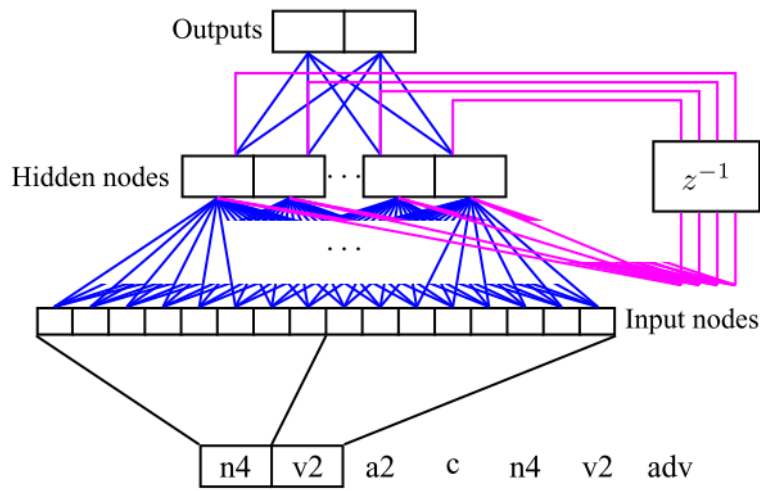

Gambar 1. Arsitektur dengan input level kata [15]

Ada yang input layernya menggunakan level kata[15][5][14] dengan arsitektur seperti pada gambar 1 . bahkan pada level karakter[5] seperti pada gambar 2 . 


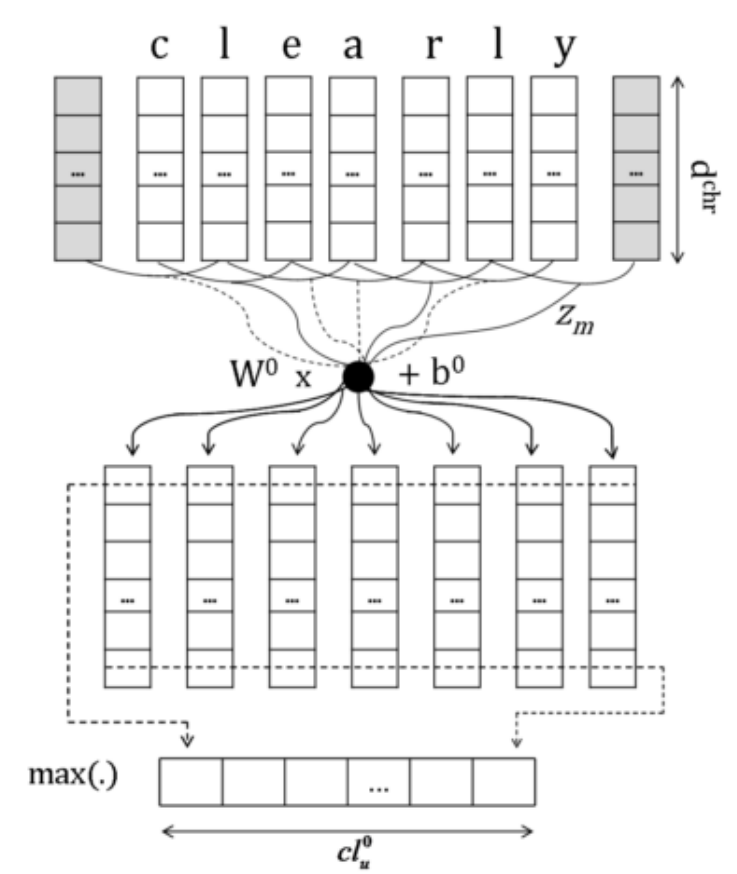

Gambar 2. Arsitektur dengan input level karakter [9]

\section{Analisis Sentimen Tweet Menggunakan Backpropagation Neural Network}

Pada penelitian sentimen analisis tweet ini digunakan arsitektur rancangan yang terlihat pada gambar 3 .

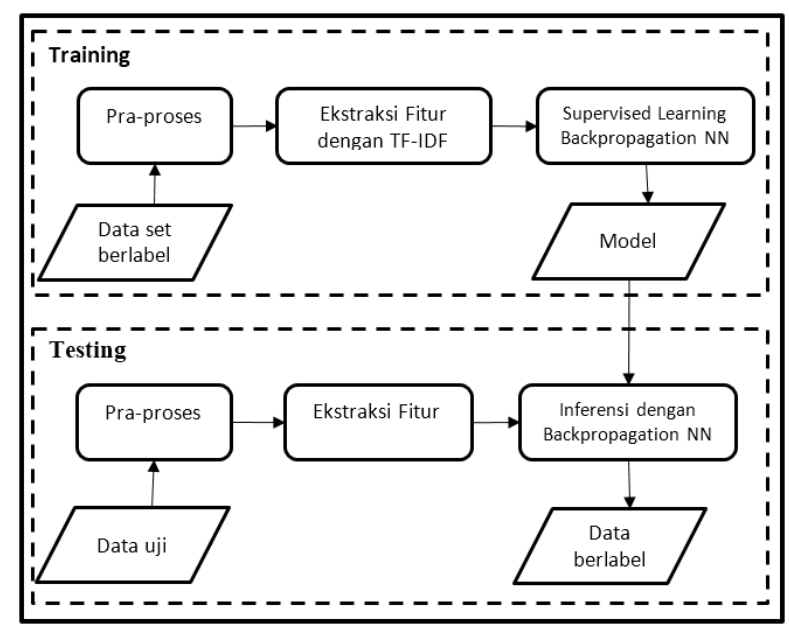

Gambar 3. Arsitektur rancangan Sentimen Analisis

Twitter menggunakan Backpropagation Neural Network

Berdasarkan gambaran rancangan arsitektur, ada dua bagian utama pada penelitian ini yaitu fase Training dan Testing. Pada fase training, data set berlabel melewati 4 proses diantaranya yaitu pra-proses, tokenisasi, ekstraksi fitur dengan TFIDF dan supervised learning dengan Backpropagation Neural Network sehingga menghasilkan model. Pada fase testing, data uji akan melewati beberapa proses seperti praprosess, tokenisasi dan inferensi menggunakan Backpropagation Neural Network yang membutuhkan data model serta menghasilkan data berlabel. Berikut dibahas lebih detil untuk bagian pada tiap fase.

\section{A. Praproses}

Pada pengolahan teks, umumnya dilakukan tahap praproses yang ditujukan untuk membersihkan dan menyamakan format teks sehingga pada proses pengolahan berikutnya lebih terstruktur. Tahap praproses ini digunakan baik pada fase training (untuk data berlabel) maupun pada fase testing (untuk data uji). Beberapa praproses yang dilakukan yaitu tansformasi $\mathrm{kata} /$ term gaul, cleaning dan normalization, stopword removal, stemming, soundex dan tokenisasi.

Transformasi kata gaul dilakukan karena tweet ditulis sebagai teks yang tidak baku, sehingga banyak ditemukan kata-kata yang tidak formal/gaul yang perlu dinormalisasi ke dalam kata yang sesuai dengan KBBI (Kamus Besar Bahasa Indonesia). Pada proses ini, digunakan kamus bahasa gaul dari situs http://www.snipertechno.com/2012/12/kamus-alayterbaru-2013.html dan http://adhitezt12.blogspot.com/2012/12/kamus-bahasaalay-lengkap.html untuk melakukan transformasi ke penulisan kata yang baku.

Cleaning dan normalization dilakukan untuk menghapus "mention” (@), "retweet”(RT) dan digit pada data set yang dianggap tidak memiliki peran dalam penentuan kelas dari tweet. Normalisasi dilakukan dengan me-lower case kan semua huruf untuk mendapatkan format yang seragam, serta penggantian semua kata-kata tidak sopan dengan kata "makian" untuk mengelompokkan ungkapan-ungkapan kekesalan tersebut.

Stopword merupakan kata-kata yang tidak memiliki arti seperti "itu", "ini”, “dan", "yang”, dst. Stopword removal atau penghapusan stopword dilakukan karena frekuensi kemunculannya yang tinggi namun tidak memiliki kontribusi, dikhawatirkan dapat menggangu proses klasifikasi. Daftar stopword didapatkan dari http://yudiwbs.wordpress.com/2008/07/23/stop-wordsuntuk-bahasa-indonesia/, juga dilakukan beberapa penambahan kata-kata yang dianggap perlu seperti "sih", "nah", "kok",dsb.

Stemming atau penghilangan imbuhan dilakukan untuk mengambil bentuk dasar dari sebuah kata yang telah mengalami morphology karna penambahan imbuhan. Misalnya 'membeli' dan 'belikan' menjadi 'beli'. Tujuan dari tahap ini yaitu menangani jika ada dua atau lebih kata berbeda namun memiliki makna yang hampir sama tetap diperlakukan sebagai 1 kata yang sama.

Soundex dilakukan untuk mengubah kata kedalam bentuk kode suara, sehingga untuk kata-kata yang pengucapannya mirip akan memiliki kode yang sama. Pada soundex juga hanya mengolah huruf-huruf konsonan dari kata, sedangkan huruf vokal dihilangkan. Berdasarkan analisa data, langkah ini dianggap perlu karena banyak kata-kata dalam data set yang dituliskan secara tidak lengkap/disingkat seperti 'dapat' ditulis 'dpt'. Ada juga beberapa kata yang sama namun ditulis secara berbeda seperti 'malas' dan 'males'. Langkah ini 
akan menghasilkan kode yang sama baik untuk kata disingkat maupun kata sama yang ditulis sedikit berbeda.

Tokenisasi dilakukan untuk memenggal tiap kata atau term yang terpisah oleh tanda baca seperti spasi, titik, koma, tanda tanya, dsb. Term-term atau token-token tersebut dipilih kembali sebagai kata yang paling mewakili tiap label sentimen pada tahap ekstraksi fitur untuk fase training. Sedangkan pada fase testing, term selanjutnya diinferensi dengan algoritma Backpropagation Neural Network.

\section{B. Ekstraksi Fitur dengan TF*IDF}

Keluaran dari praposes dan tokenisasi menghasilkan jumlah term yang banyaknya sesuai dengan data set masukannya. Term-term tersebut akan mewakili atau menjadi fitur pada text classification menggunakan backpropagation. Namun tidak semua term dijadikan fitur, fitur didapatkan dengan cara mengambil 50 kata/term terbaik dari data training yang mewakili tiap kelas target (netral, positif, dan negatif). Dari setiap kelompok tweet berdasarkan kelas target akan memiliki 50 term yang masing-masing akan dimerge secara distinct. Total term yang didapatkan akan menjadi fitur (input perceptron) pada jaringan backpropagation.

Perhitungan yang digunakan untuk mendapatkan top 50 term terbaik dari tiap kelompok tweet menggunakan pembobotan TF*IDF (Term Frequency-Inverse Document Frequency). Nilai TF*IDF yang tinggi menggambarkan bahwa term tersebut merupakan term yang penting dari suatu kelompok tweet (kelompok berdasar kelas target), dilihat dari kemunculannya yang intens dalam kelompoknya namun tidak umum untuk kelompok lain. Misalnya, kata "makian" akan menjadi penting untuk kelas negatif tetapi tidak banyak dijumpai pada kelas lainnya.

\section{Supervised Learning Backpropagation Neural Network}

Pada penelitian sentiment analisis ini, digunakan metode pembelajaran terbimbing dengan algoritma Backpropagation Neural Network (BNN) dengan arsitektur seperti gambar 4. Fungsi aktivasi untuk setiap perceptron yang dipilih ialah sigmoid.

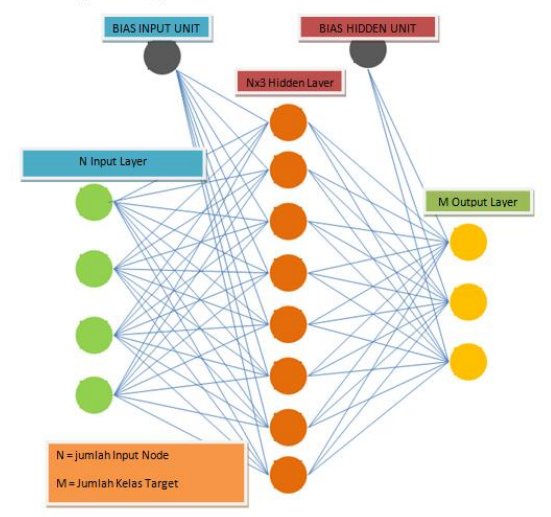

Gambar 4. Arsitektur BNN untuk Sentimen Analisis Tweet
Setiap node pada input merepresentasikan satu buah kata atau term yang dijadikan fitur. Sehingga jika terdapat 50 term yang akan dijadikan fitur, maka input pada BNN merupakan array double sejumlah 50 elemen. Pada fase training, term-term tiap tweet dipetakan sesuai dengan 50 term terpilih pada node input, jika terdapat term yang sama maka akan bernilai 1 dan 0 jika sebaliknya. Selain itu, tiap-tiap tweet juga telah terlabeli sesuai kelasnya (negatif, positif atau netral). Berdasarkan data set berlabel tersebut akan dilakukan pembelajaran terbimbing sehingga diakhir didapatkan bobot yang sesuai dengan data pembelajaran yang kemudian disimpan sebagai model.

\section{Ekstraksi Fitur}

Tahap ekstraksi fitur ini dilakukan terhadap data uji (tweet tidak berlabel) dengan cara menyamakan term yang dihasilkan dari praproses dengan daftar term yang sudah diekstraksi dari fase training menggunakan TFIDF. Jika ada term yang sama maka elemen fitur bernilai 1, jika tidak maka bernilai 0 .

\section{E. Inferensi dengan Backpropagation Neural Network}

Proses ini dilakukan untuk menginferensi atau mengklasifikasi fitur dari data uji, terhadap tiga kelas yang ada. Tahap ini membutuhkan model dari BNN dari hasil training. Pada tahap ini model mengandung bobot yang sudah sesuai dengan hasil training, yang kemudian fitur input dihitung terhadap bobot-bobot ditiap layer sehingga outputnya merepresentasikan kelas dari data uji. Jika hasil akhir output secara berurutan ialah 100 maka data uji berlabel kelas negatif, 010 kelas positif dan 001 kelas netral.

\section{Hasil dan Pembahasan}

\subsection{Skenario Eksperimen}

Ketentuan penggunaan Backpropagation Neural Network pada eksperimen ini yaitu, misal

1. jumlah term yang diekstraksi fitur dengan TF*IDF $(\mathrm{N})=90$

2. input Layer $\rightarrow \mathrm{N}=90(+1$ Bias Unit $)=91$ Perceptron

3. hidden Layer $\rightarrow \mathrm{N}$ x $3=90 * 3(+1$ Bias Unit $)=$ 271 Perceptron

4. ouput Layer $\rightarrow \mathrm{M}=3$ (Negatif, Positif, Netral)

5. learning rate $\rightarrow 0.1$

6. stopping criterion untuk training menggunakan BNN adalah dengan galat $10 \%$ atau maksimal iterasi 500 .

Pada eksperimen ini total data set yang digunakan yaitu 944 tweet dimana tweet-tweet tersebut terdiri dari kelas netral (500 tweet), positif (254 tweet), dan negatif (190 tweet). Seluruh tweet kemudian dibagi menjadi 2 bagian, $2 / 3$ untuk data training (630 tweet) dan $1 / 3$ untuk data testing (314 tweet).

Pada pengujian dilakukan uji coba terhadap beberapa jumlah fitur term yang diambil yaitu sebanyak 30, 50, 70 dan 100 term per kelas target. Skema selanjutnya yaitu 
kedua data training dan data testing akan dibagi menjadi 5 grup yaitu:

Grup I :data hanya di tokenisasi, tanpa praproses lain.

Grup II :data dengan praproses transformasi kata gaul, cleaning \& normalization, tokenisasi.

Grup III :data dengan praproses transformasi kata gaul, cleaning \& normalization, stopword removal, tokenisasi.

GrupVI :data dengan praproses transformasi kata gaul, cleaning \& normalization, stopword removal, stemming, tokenisasi.

Grup V :data dengan praproses transformasi kata gaul, cleaning \& normalization, stopword removal, stemming, soundex, tokenisasi.

Eksperimen ini diukur menggunakan 3 jenis pengukuran yaitu:

1. Correct classified (C), didapatkan dari prosentase hasil kata yang terlabeli dengan benar dibagi total seluruh kata yang diuji.

2. Precision (P), didapatkan dari prosentase penjumlahan precision semua kelas dibagi total kelas. Sedangkan nilai precision tiap kelas didapatkan dengan menghitung jumlah kata yang terklasifikasi benar terhadap sebuah kelas dibagi total kata yang terklasifikasi kekelas tersebut.

3. Recall $(\mathrm{R})$, didapatkan dari prosentase penjumlahan recall semua kelas dibagi total kelas. Sedangkan nilai recall tiap kelas didapatkan dengan menghitung jumlah kata yang terklasifikasi benar terhadap sebuah kelas dibagi jumlah kata yang sebenarnya merupakan member dari kelas tersebut.

\subsection{Hasil}

Setelah dilakukan eksperimen didapatkan hasil untuk tiap grup dengan variasi jumlah term perkelas target seperti pada tabel-tabel berikut.

Tabel 1. Hasil pengujian Grup I

\begin{tabular}{llllll}
\hline & $\begin{array}{l}\mathbf{3 0} \\
\text { term } \\
\text { /kelas } \\
\text { target } \\
(\boldsymbol{\%})\end{array}$ & $\begin{array}{l}\mathbf{5 0} \\
\text { term } \\
\text { /kelas } \\
\text { target } \\
(\boldsymbol{\%})\end{array}$ & $\begin{array}{l}\mathbf{7 0} \\
\text { term } \\
/ \text { kelas } \\
\text { target } \\
(\boldsymbol{\%})\end{array}$ & $\begin{array}{l}\mathbf{1 0 0} \\
\text { term } \\
/ \text { kelas } \\
\text { target } \\
(\boldsymbol{\%})\end{array}$ & $\begin{array}{l}\text { rata- } \\
\text { rata } \\
(\boldsymbol{\%})\end{array}$ \\
\hline $\mathbf{C}$ & 60.82 & 69.11 & 68.47 & 73.56 & 67.99 \\
\hline $\mathbf{P}$ & 59.81 & 72.04 & 68.17 & 76.99 & 69.25 \\
\hline $\mathbf{R}$ & 57.08 & 62.24 & 63.28 & 66.73 & 62.33 \\
\hline
\end{tabular}

Tabel 1. adalah hasil pengukuran untuk Grup I dimana semua data set tidak dilakukan praproses kecuali tokenisasi. Dari tabel tersebut terlihat jika hasil pengukuran terbaik terjadi pada pengujian dengan 100 term/kelas target. Sedang hasil terendah dari pengujian dengan 30 term/ kelas target.
Tabel 2. Hasil pengujian Grup II

\begin{tabular}{|c|c|c|c|c|c|}
\hline & $\begin{array}{c}30 \\
\text { term } \\
\text { /kelas } \\
\text { target } \\
(\%)\end{array}$ & $\begin{array}{c}50 \\
\text { term } \\
\text { /kelas } \\
\text { target } \\
(\%)\end{array}$ & $\begin{array}{c}70 \\
\text { term } \\
\text { /kelas } \\
\text { target } \\
(\%)\end{array}$ & $\begin{array}{c}100 \text { term } \\
\text { /kelas } \\
\text { target } \\
(\%)\end{array}$ & $\begin{array}{c}\text { rata- } \\
\text { rata } \\
(\%)\end{array}$ \\
\hline C & 72.61 & 78.34 & 77.07 & 77.07 & 76.27 \\
\hline $\mathbf{P}$ & 72.12 & 84.21 & 82.93 & 83.73 & 80.74 \\
\hline $\mathbf{R}$ & 68.26 & 72.63 & 70.54 & 70.63 & 70.51 \\
\hline
\end{tabular}

Hasil pengukuran untuk pengujian Grup II dimana data set melewati tahap praproses transformasi kata gaul, cleaning \& normalization, tokenisasi ada pada tabel 2 . Secara rata-rata hasil pada Grup II lebih baik dibandingkan dengan Grup I, dengan hasil paling baik dengan perbedaan tipis ditujukan pada pengujian dengan $50 \mathrm{term} /$ kelas target.

Tabel 3. Hasil pengujian Grup III

\begin{tabular}{|c|c|c|c|c|c|}
\hline & $\begin{array}{c}30 \\
\text { term } \\
\text { /kelas } \\
\text { target } \\
(\%)\end{array}$ & $\begin{array}{c}50 \\
\text { term } \\
\text { /kelas } \\
\text { target } \\
(\%)\end{array}$ & $\begin{array}{c}70 \\
\text { term } \\
\text { /kelas } \\
\text { target } \\
(\%)\end{array}$ & $\begin{array}{c}100 \\
\text { term } \\
\text { /kelas } \\
\text { target } \\
(\%)\end{array}$ & $\begin{array}{l}\text { ata- } \\
\text { rata } \\
(\%)\end{array}$ \\
\hline $\mathrm{C}$ & 76.43 & 74.20 & 78.98 & 75.15 & 76.19 \\
\hline $\mathbf{P}$ & 80.99 & 79.73 & 81.22 & 80.98 & 80.73 \\
\hline $\mathbf{R}$ & 71.01 & 67.72 & 75.35 & 68.43 & 70.62 \\
\hline
\end{tabular}

Skenario untuk Group III hampir sama dengan Grup II dengan penambahan praproses stopword removal. Hasil pengukuran secara umum pada Grup III tidak jauh berbeda dengan Grup II. Dimana hasil terbaik diperoleh pada pengujian $70 \mathrm{term} /$ kelas target.

Tabel 4. Hasil pengujian Grup IV

\begin{tabular}{cccccc}
\hline $\begin{array}{c}30 \text { term } \\
\text { /kelas } \\
\text { target } \\
(\boldsymbol{\%})\end{array}$ & $\begin{array}{c}\mathbf{5 0} \\
\text { term } \\
\text { /kelas } \\
\text { target } \\
(\boldsymbol{\%})\end{array}$ & $\begin{array}{c}\mathbf{7 0} \\
\text { term } \\
\text { /kelas } \\
\text { target } \\
(\boldsymbol{\%})\end{array}$ & $\begin{array}{c}\mathbf{1 0 0 t e r m} \\
\text { /kelas } \\
\text { target } \\
(\boldsymbol{\%})\end{array}$ & $\begin{array}{c}\text { rata- } \\
\text { rata } \\
(\boldsymbol{\%})\end{array}$ \\
\hline $\mathbf{C}$ & 76.43 & 75.47 & 76.11 & 78.02 & 76.5 \\
\hline $\mathbf{P}$ & 80.86 & 81.71 & 81.13 & 80.03 & 80.93 \\
\hline $\mathbf{R}$ & 71.10 & 68.73 & 69.71 & 74.15 & 70.92 \\
\hline
\end{tabular}

Pada eksperimen untuk Grup IV juga masih memiliki rata-rata hasil pengukuran yang mirip dengan Grup II dan III. Data set pada Grup IV melalui tahap praproses transformasi kata gaul, cleaning \& normalization, stopword removal, stemming, dan tokenisasi. Hasil dengan correct classified dan recall terbaik yaitu pengujian untuk $100 \mathrm{term} /$ kelas target.

Tabel 5. Hasil pengujian Grup V

\begin{tabular}{|c|c|c|c|c|}
\hline $\begin{array}{c}30 \\
\text { term } \\
\text { /kelas } \\
\text { target } \\
(\%)\end{array}$ & $\begin{array}{c}50 \\
\text { term } \\
\text { /kelas } \\
\text { target } \\
(\%)\end{array}$ & $\begin{array}{c}70 \\
\text { term } \\
\text { /kelas } \\
\text { target } \\
(\%)\end{array}$ & $\begin{array}{c}\text { 100term } \\
\text { /kelas } \\
\text { target } \\
(\%)\end{array}$ & $\begin{array}{c}\text { rata- } \\
\text { rata } \\
(\%)\end{array}$ \\
\hline
\end{tabular}




\begin{tabular}{llllll}
\hline $\mathbf{C}$ & 71.33 & 72.93 & 71.33 & 72.61 & 72.05 \\
\hline $\mathbf{P}$ & 73.13 & 73.64 & 74.05 & 76.53 & 74.33 \\
\hline $\mathbf{R}$ & 66.38 & 69.43 & 66.47 & 66.43 & 67.17 \\
\hline
\end{tabular}

Pengujian Grup terakhir pada tabel 5. mengalami penurunan hasil pengukuran, dimana data set mengalami semua praproses yaitu transformasi kata gaul, cleaning \& normalization, stopword removal, stemming, soundex.

\section{Simpulan}

Hasil pengujian pada sentimen analisis menunjukkan jika tahap praproses diperlukan untuk meningkatkan akurasi hasil klasifikasi. Sedangkan bentuk praproses yang paling baik ditunjukkan oleh penggunaan transformasi kata gaul, cleaning (retweet dan mention) dan normalisasi (case folding dan perubahan makian). Sedangkan praproses soundex memberikan dampak penurunan akurasi. Sementara jumlah fitur atau term sebagai data input tidak banyak berpengaruh terhadap hasil. Secara keseluruhan, metode Backpropagation Neural Network memberikan performa yang baik.

\section{Daftar Pustaka}

[1] A. Agarwal, B. Xie, I. Vovsha, O. Rambow, and R. Passonneau, "Sentiment analysis of Twitter data," Assoc. Comput. Linguist., 2011.

[2] A. Go, R. Bhayani, and L. Huang, "Twitter Sentiment Classification using Distant Supervision," 2009.

[3] B. Liu, "Sentiment Analysis and Subjectivity," 2010.

[4] B. Pang, L. Lee, H. Rd, and S. Jose, "Thumbs up ? Sentiment Classification using Machine Learning Techniques," 2002.

[5] C. N. dos Santos and M. Gatti, "Deep Convolutional Neural Networks for Sentiment Analysis of Short Texts," Coling-2014, 2014.

[6] C. Scheible, "Unsupervised Sentiment Analysis with a Simple and Fast Bayesian Model using Part-of-Speech Feature Selection," vol. 2012, 2012.

[7] E. Kouloumpis, T. Wilson, and J. Moore, "Twitter sentiment analysis: The good the bad and the omg!," Proc. Fifth Int. AAAI Conf. Weblogs Soc. Media (ICWSM 11), 2011.

[8] G. Salton and M. McGill, Introduction to modern Information Retrieval. McGraw-Hill, 1983.

[9] I. F. Rozi, S. Hadi, and E. Achmad, "Implementasi Opinion Mining ( Analisis Sentimen ) untuk Ekstraksi Data Opini Publik pada Perguruan Tinggi," vol. 6, no. 1, 2012.

[10] J. Martineau, J. Martineau, T. Finin, T. Finin, C. Fink, C. Fink, C. Piatko, C. Piatko, J. Mayfield, J. Mayfield, Z. Syed, Z. Syed, Others, and Others, "Delta TFIDF: An Improved Feature Space for Sentiment Analysis," Proc. Second Int. Conf. Weblogs Soc. Media (ICWSM, vol. 29, no. May,
2008.

[11] K. Ghag, "SentiTFIDF - Sentiment Classification using Relative Term Frequency Inverse Document Frequency," vol. 5, no. 2, 2014.

[12] P. Aliandu, "Sentiment analysis on indonesian tweet," 2013.

[13] P. D. Turney, "Thumbs Up or Thumbs Down? Semantic Orientation Applied to Unsupervised Classification of Reviews," no. July, 2002.

[14] R. Socher, A. Perelygin, J. Y. Wu, J. Chuang, C. D. Manning, A. Y. Ng, and C. Potts, "Recursive Deep Models for Semantic Compositionality Over a Sentiment Treebank," 2013.

[15] S. Roa and F. Nino, "Classification of Natural Language Sentences using Neural Networks," 2003.

[16] T. M. Mitchell, Machine Learning. McGraw-Hill, 1997.

[17] X. Hu, J. Tang, H. Gao, and H. Liu, "Unsupervised Sentiment Analysis with Emotional Signals," 2013.

Maulana Aziz Assuja, lahir di Sindang Anom, 24 Nopember 1986. Memperoleh gelar D4 di Program Studi Teknik Informatika, Institut Teknologi Sepuluh November di Surabaya pada tahun 2009. Kemudian pada tahun 2015 memperoleh gelar S2 di Program Studi Informatika, Institut Teknologi Bandung. Saat ini bekerja aktif sebagai staf pengajar di STMIK-AMIK Teknokrat Lampung.

Saniati, lahir di Tarakan, 14 Februari 1988. Memperoleh gelar D4 di Program Studi Teknik Informatika, Institut Teknologi Sepuluh November di Surabaya pada tahun 2009. Kemudian pada tahun 2014 memperoleh gelar S2 di Program Studi Informatika, Institut Teknologi Bandung. Saat ini bekerja aktif sebagai staf pengajar di STMIK-AMIK Teknokrat Lampung. 